US Army Corps

of Engineers ${ }_{\circledast}$

Engineer Research and

Development Center

Engineered Resilient Systems

\title{
Integrated Rule-Oriented Data System (IRODS) and High Performance Computing (HPC) Project Management Plan
}

Kevin D. Winters, Mark A. Cowan, Glover E. George,

Megan E. Gonzalez, Brian Priest, Omar Morris,

and Jonathan Landrum

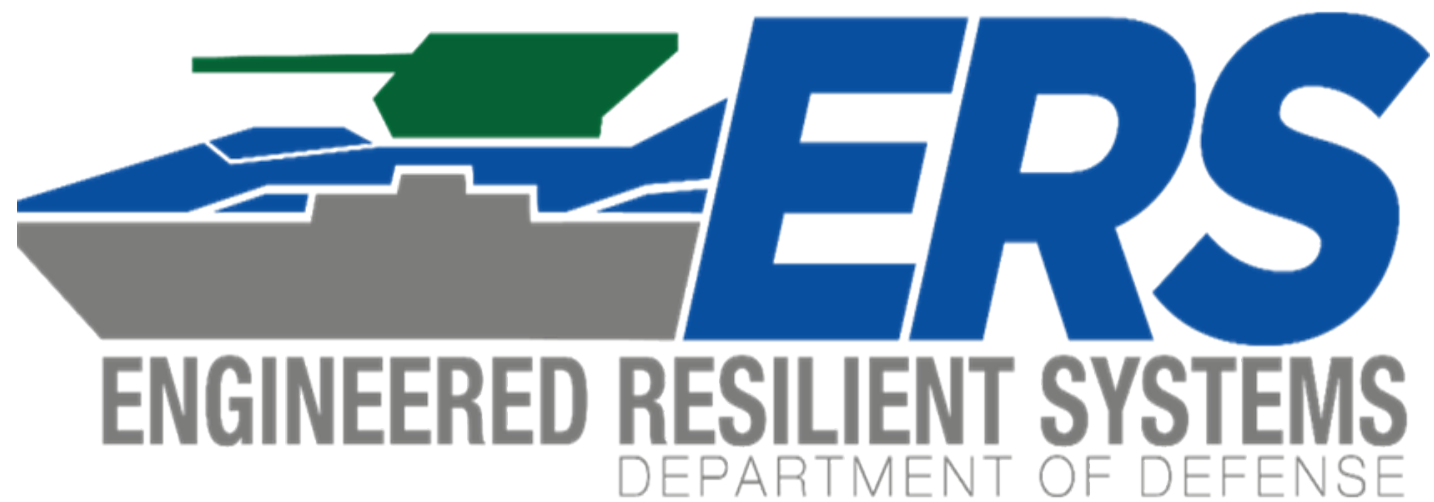


The U.S. Army Engineer Research and Development Center (ERDC) solves the nation's toughest engineering and environmental challenges. ERDC develops innovative solutions in civil and military engineering, geospatial sciences, water resources, and environmental sciences for the Army, the Department of Defense, civilian agencies, and our nation's public good. Find out more at www.erdc.usace.army.mil.

To search for other technical reports published by ERDC, visit the ERDC online library at http://acwc.sdp.sirsi.net/client/default. 


\section{Integrated Rule-Oriented Data System (iRODS) and High Performance Computing (HPC) Project Management Plan}

Kevin D. Winters, Mark A. Cowan, Glover E. George, and Megan E. Gonzalez

U.S. Army Engineer Research and Development Center (ERDC)

Information Technology Laboratory (ITL)

3909 Halls Ferry Road

Vicksburg, MS 39180-6199

Brian Priest, Omar Morris, and Jonathan Landrum

Geocent New Orleans, LA.

2219 Lakeshore Dr \# 300

New Orleans, LA 70122

Final Report

Approved for public release; distribution is unlimited.

Prepared for Headquarters, U.S. Army Corps of Engineers

Washington, DC 20314-1000

Under Work Unit 92L5D8 


\section{Abstract}

This project management plan (PMP) is established to provide guidance on the management of the Integrated Rule-Oriented Data System (iRODS) Project. The PMP and its associated plans are the primary source of information for how the project will be planned, executed, monitored, controlled, and closed. The intended audience of the plan is all project stakeholders including the project manager (PM), Engineered Resilient Systems (ERS), High-Performance Computing (HPC), and the Geocent project team members.

DISCLAIMER: The contents of this report are not to be used for advertising, publication, or promotional purposes. Citation of trade names does not constitute an official endorsement or approval of the use of such commercial products. All product names and trademarks cited are the property of their respective owners. The findings of this report are not to be construed as an official Department of the Army position unless so designated by other authorized documents. 


\section{Contents}

Abstract....................................................................................................................................... if

Figures and Tables....................................................................................................................................

Preface ............................................................................................................................................ vi

1 Introduction........................................................................................................................ 1

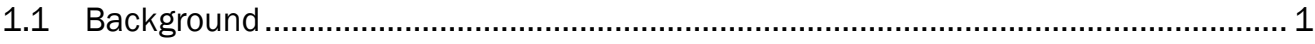

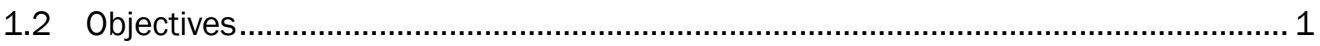

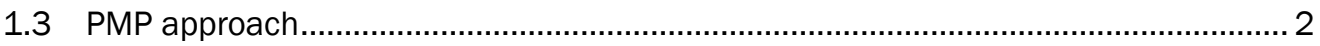

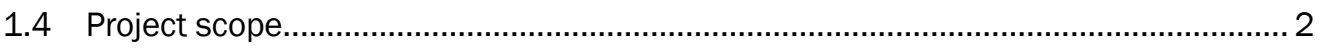

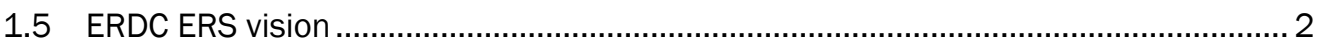

1.5.1 Phase I - Test environment build-out......................................................................... 3

1.5.2 Phase II - Web GUI customizations and auditing dashboards ...................................... 3

1.5.3 Phase III - Data migration for ERS Test Teams............................................................ 3

1.5.4 Phase IV - Test planning and execution ..................................................................... 3

1.5.5 Phase $V$ - Production migration analysis.................................................................. 3

1.6 Assumptions/constraints .............................................................................. 4

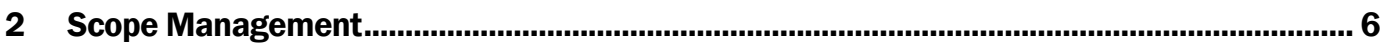

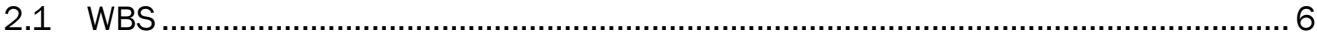

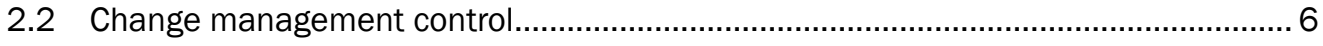

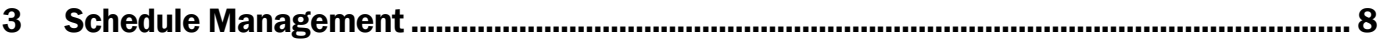

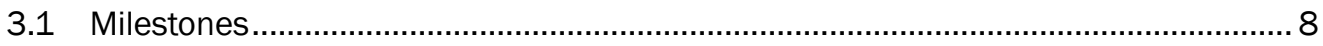

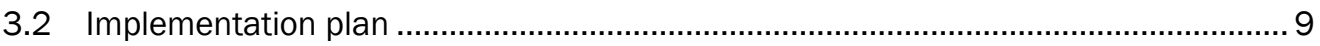

3.3 Scrum agile process ................................................................................ 10

4 Cost/Budget Management............................................................................................12

5 Quality Management ......................................................................................................................13

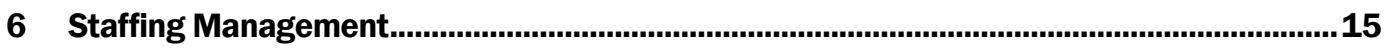

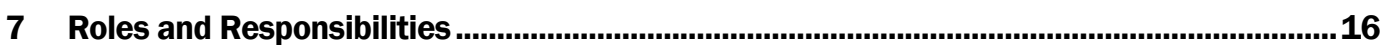

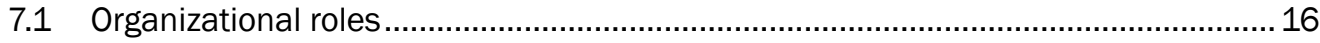

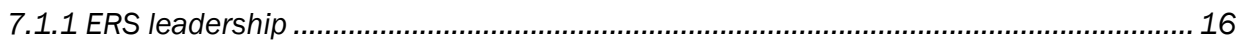

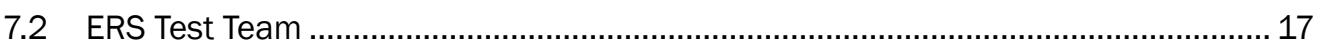

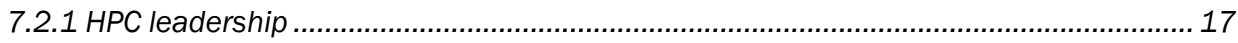

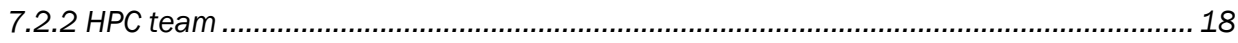

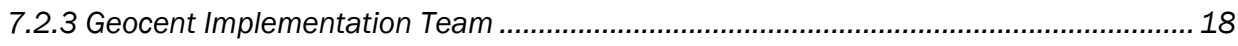

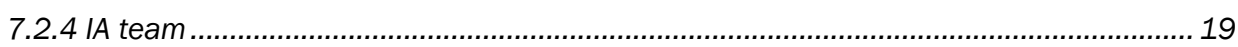

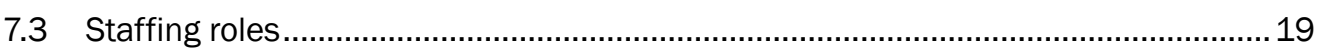

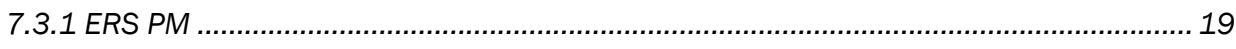

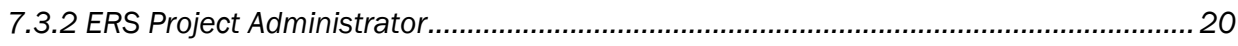




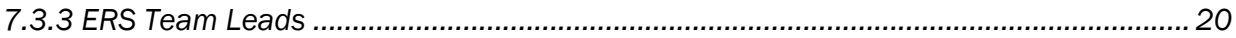

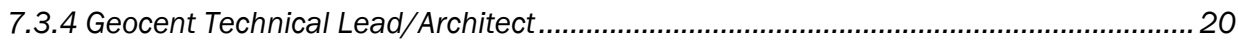

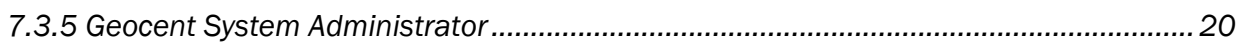

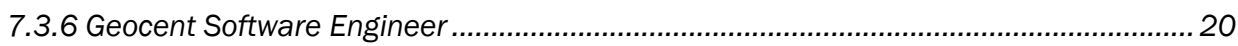

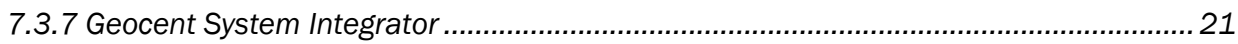

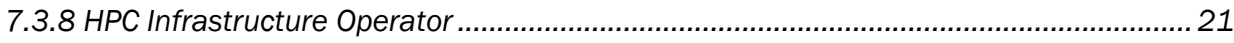

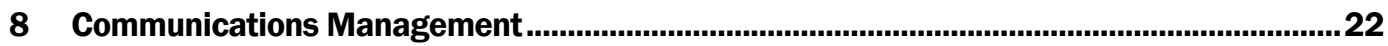

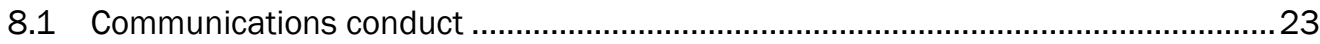

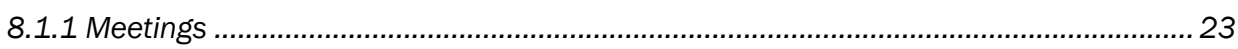

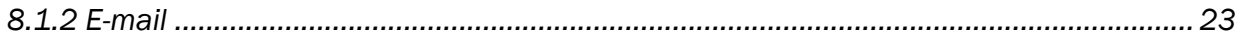

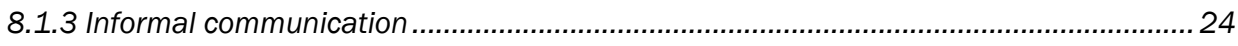

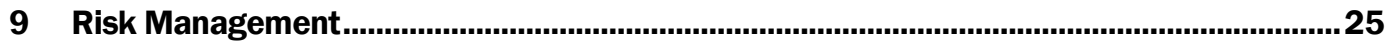

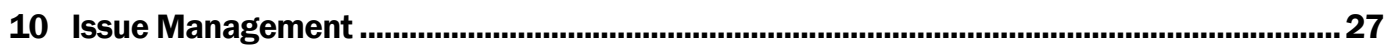

11 Responsible, Accountable, Consulted, and Informed (RACI) Diagram .............................28

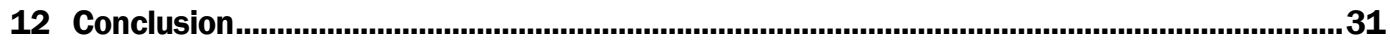

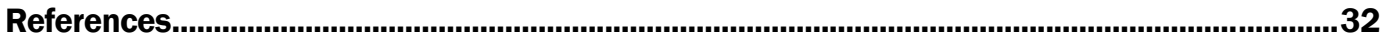

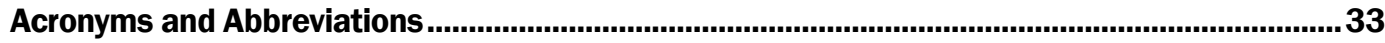

Report Documentation Page 


\section{Figures and Tables}

\section{Figures}

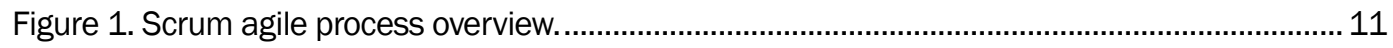

\section{Tables}

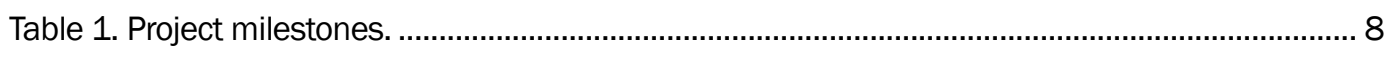

Table 2. Communication matrix....................................................................................... 22

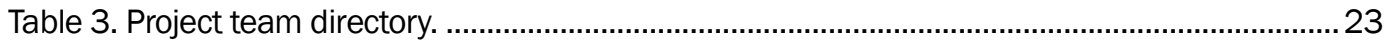

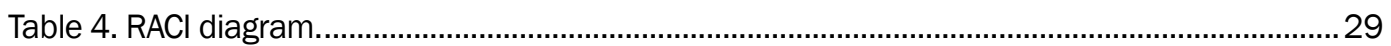




\section{Preface}

This project management plan is a deliverable product under the Engineered Resilient Systems (ERS) Program, Data Analytics Work Package, Collaborative Tradespace Analytics Work Unit 92L5D8. Dr. Owen J. Eslinger was the Program Manager, and Dr. Robert M. Wallace was the Technical Director of the ERS program.

The work was performed by the Computational Analysis Branch (CAB) of the Computational Science and Engineering Division (CSED), U.S. Army Engineer Research and Development Center (ERDC), Information Technology Laboratory (ITL), Vicksburg, MS. At the time of publication, Dr. Jeffrey L. Hensley was Chief, CAB; Dr. Jerrell R. Ballard, Jr. was the Chief, CSED; Ms. Patti S. Duett was the Deputy Director of ITL and the Director was Dr. David A. Horner.

COL Teresa A. Schlosser was the Commander of ERDC, and Dr. David W. Pittman was the Director. 


\section{Introduction}

\subsection{Background}

Engineered Resilient Systems (ERS) has requested that Geocent perform an initial engineering analysis to determine the feasibility of leveraging the Integrated Rule-Oriented Data System (iRODS) within the highperformance computing (HPC) environment to provide advanced data management capabilities. ERS leadership has approved the iRODS analysis to move forward for project initiation of the development of an iRODS prototype within the HPC environment.

The desired project end state is to host iRODS within the HPC environment and provide the capabilities to all ERS work package teams. The deployment of iRODS within the HPC environment is expected to simplify the management of data and metadata, increase the discoverability of data, and provide fine-grained security and auditing of data access.

This project management plan (PMP) is established to provide guidance on the management of the iRODS Project. The PMP and its associated plans are the primary source of information for how the project will be planned, executed, monitored, controlled, and closed. The intended audience of the plan is all project stakeholders including the Project Manager (PM), ERS, HPC, and the Geocent project team members.

\subsection{Objectives}

"ERDC's ERS business area combines advanced engineering techniques with high-performance computing to develop concepts and tools that significantly amplify design options examined during early stages of the acquisition process. Techniques result in trade spaces that can be generated in hours rather than months and are thousands of times larger and hundreds of times more accurate than those created via traditional methods" (ERDC 2019).

To support the various ERS work package teams in their mission, the iRODS project aims to provide added capabilities to the teams' workflows that will enable comprehensive data and metadata management over the 
vast amount of data created as a result of their work. The project will greatly improve data discovery, automated data governance, storage utilization, and provide fine-grained security controls to support sharing and collaboration.

\subsection{PMP approach}

The PM has the overall authority and responsibility for managing and executing this project according to this PMP. The project team will primarily consist of personnel from ERS, HPC, and Geocent. The ERS Test Team consists of team members from the individual work package teams selected by the PM to participate in testing. The PM will work with all resources to perform project planning and will coordinate efforts with other organizational units as required for the successful execution. This project plan will be reviewed and approved by the ERS leadership, and all funding decisions will be made by ERS leadership.

The PM is responsible for communicating with organizational managers on the progress and performance of each project resource. Additionally, formal project reviews will be conducted with the ERS leadership each month, or as otherwise agreed to by the program leadership.

\subsection{Project scope}

The scope of the iRODS Project includes the planning, design, provisioning, data migration, configuration of rules and policies, custom software engineering, and testing (functional, performance, and recovery) of the iRODS prototype within the HPC test environment. The iRODS prototype will meet the requirements outlined in the ERS iRODS Requirements Document. The scope of this project also includes the update or development of related processes, procedures, and other documentation required for the use and management of the infrastructure. Testing will occur when the ERS Test Teams are able to operate the deployed capabilities within the HPC test environment.

\subsection{ERDC ERS vision}

The iRODS prototype will be developed in a test environment and conducted over the following five phases:

- Phase I Test environment build-out 
- Phase II Web graphic user interface (GUI) customizations and auditing dashboards

- Phase III Data migration for ERS Test Teams

- Phase IV Test planning and execution

- Phase V Production migration analysis

\subsubsection{Phase I - Test environment build-out}

- Prepare Security Test Plan and Request for Change (RFC) for the iRODS test environment

- Configure software on all virtual machines within the test environment

- Integrate with existing DoD Supercomputing Resource Center (DSRC) Kerberos Key Distribution Center (KDC) for authentication

- Smoke-test all major functionality of the installed software packages

\subsubsection{Phase II - Web GUI customizations and auditing dashboards}

- Configure custom management GUIs for system health, storage allocation, data transfers, and audit record review

- Configure team-specific dashboards to view team resource usage, group, and user permissions

\subsubsection{Phase III - Data migration for ERS Test Teams}

- Configure storage space for each of the identified ERS test teams

- Configure rules and policies according to requirements documentation

- Assist with test team's data migration into iRODS and support functional testing

\subsubsection{Phase IV - Test planning and execution}

- Develop performance test plans to capture benchmark results from test teams use cases

- Performance-tuning of iRODS and supporting applications to maximize performance results

- Additional performance test runs to identify optimal configurations

- Provide performance testing results to ERDC

\subsubsection{Phase V - Production migration analysis}

- Additional requirements collected during the team on-boarding and migration activities will be reviewed through the ERS requirements 
management process. Approved requirements will be added to the requirements document.

- Production architecture document created based on findings proof-ofconcept functional and performance testing activities.

\subsection{Assumptions/constraints}

The following list of assumptions and constraints exist for this project:

- Phase I - Test environment build-out

- The host virtual machines (VMs) identified in the iRODS architecture design document are created by HPC personnel in a test subnet and Geocent is provided administrative access to the VMs.

- The ports and protocols identified in the iRODS architecture design document are approved and opened by the HPC network engineer.

- The specific software listed in the iRODS architecture design document is made available through the DSRC satellite package repository.

- Geocent implementation team completes required training in order to achieve administrative access to the iRODS host VMs.

- Access to the iRODS prototype is made available from HPC resources outside of the iRODS test subnet to simulate HPC integration tests.

- Phase II - Web GUI customizations and auditing dashboards

- Phase I install of Web GUI and auditing dashboard components are completed and initial functional testing is a success.

- Web GUI customization and auditing dashboard features are prioritized by ERS.

- Phase III - Data migration for ERS test teams

- ERS Team Leads identify data or assist in the creation of similar test data to be used for the prototype functional and performance testing.

- Geocent will assist in the migration and/or creation of test data for the prototype.

- Geocent will be approved to access any test data used for the prototype. 
- Phase IV - Test planning and execution

- ERS Team Leads will assist in the functional and performance testing of the iRODS prototype.

- Geocent will assist the ERS test teams during testing and conduct functional and performance testing.

- The PM, ERS Team Leads, and Geocent will all contribute input to the test cases referenced in the Quality Management Plan.

- Phase V - Production migration analysis

- Prototype testing is successful and accepted. 


\section{Scope Management}

Scope management for the iRODS Project will be the sole responsibility of the PM. The scope for this project is defined by the scope statement in Section 1.3 and the Work Breakdown Structure (WBS) is defined in Section 2.1.

Proposed scope changes may be initiated by the iRODS PM, stakeholders, or any member of the project team. All change requests will be submitted to the PM who will then evaluate the requested change and consult with the appropriate stakeholders (e.g., ERS PM, HPC, Information Assurance [IA]) for concurrence. Upon approval of scope changes, the PM will update all project documents and communicate the change to all stakeholders. Based on feedback and input from the PM and stakeholders, ERS is responsible for the acceptance of the final project deliverables and project scope. This acceptance will be based on a review of all project documentation, prototype testing results, and completion of all tasks/work packages.

\subsection{WBS}

The WBS for this project will cover the following planned phases for the effort:

- Phase I Test environment build-out

- Phase II Web GUI customizations and auditing dashboards

- Phase III Data migration for ERS Test Teams

- Phase IV Test planning and execution

- Phase V Production migration analysis

The WBS will be managed using Microsoft Project and will be initially baselined during project kick-off activities. Changes to the WBS will be controlled by the PM and follow the change management control process.

\subsection{Change management control}

Change management for the iRODS Project will fall within the Change Management Plan and associated processes. At a high level, this means that any changes to the agreed scope of this project or the resources required to complete it must be submitted to the PM, assessed by relevant stakeholders, and finally, approved by the PM. 
For changes that specifically impact the IA posture or HPC infrastructure, an existing DSRC RFC process will be followed to request the change and have it reviewed by the appropriate personnel. 


\section{Schedule Management}

The PM will collect input according to identified tasks by the different organizations, and will facilitate schedule deconfliction as required. Once a preliminary schedule has been developed, it will be reviewed by the Project Team and resources will be tentatively assigned to project tasks by the responsible organization. The Project Team and resources must agree to the proposed task assignments, durations, and schedule. Once this is achieved, the PM will review and approve the schedule, which will thenbe managed as a baseline.

For minor changes to the agreed schedule baseline, the PM has the discretion to update the schedule accordingly. However, if a schedule change will negatively impact the completion of the currently executing phase (i.e., delay completion by more than one month), the PM will review the change to determine if this would result in a change in scope. If the schedule impact is a result of a scope change, this will be processed according to the change control process identified in this report. In all cases, the PM will be notified immediately and will provide guidance on how to continue forward with respect to the schedule. The PM will maintain the intergrated master schedule (IMS) document and it will be stored in a mutually agreeable location.

\subsection{Milestones}

Table 1 lists the high-level milestones for this project along with their estimated target sprint to be completed.

Table 1. Project milestones.

\begin{tabular}{|l|l|}
\hline Milestones & $\begin{array}{c}\text { Timeline (target } \\
\text { Sprint) }\end{array}$ \\
\hline Kick-off & \\
\hline Kick-off meeting & Sprint 0 \\
\hline On-boarding of new team members & Sprint 0 \\
\hline Required training/credentialing completed & Sprint 0 \\
\hline Schedule baseline set & Sprint 0 \\
\hline Phase I: Test Environment Build-Out & \\
\hline iRODS host VMs and test VLAN are created & Sprint 1 \\
\hline iRODS software installed and configured & Sprint 2 \\
\hline Kerberos authentication complete & Sprint 3 \\
\hline Splunk integration complete & Sprint 4 \\
\hline
\end{tabular}




\begin{tabular}{|l|l|}
\hline Milestones & $\begin{array}{l}\text { Timeline (target } \\
\text { Sprint) }\end{array}$ \\
\hline Auditing framework installed and configured & Sprint 5 \\
\hline Web GUI installed and configured & Sprint 5 \\
\hline Baseline functional testing executed & Sprint 6 \\
\hline Documentation: User Guide complete & Sprint 6 \\
\hline Phase II: Web GUI Customizations and Auditing Dashboards & \\
\hline Web GUI enhancement designs & Sprint 7 \\
\hline Web GUI enhancement prioritization & Sprint 7 \\
\hline Auditing dashboard designs & Sprint 7 \\
\hline Auditing dashboard prioritization & Sprint 7 \\
\hline Web GUI development started & Sprint 8 \\
\hline Auditing dashboards started & Sprint 8 \\
\hline Web GUI development completed & Sprint 10 \\
\hline Auditing dashboards completed & Sprint 10 \\
\hline Phase III: Data Migration for ERS Test Teams & \\
\hline Landing Zones configured & Sprint 11 \\
\hline Groups/Users permissions configured & Sprint 12 \\
\hline Test cases developed/reviewed & Sprint 12 \\
\hline Test data for each team migrated & Sprint 13 \\
\hline Additional custom test data created/loaded & Sprint 13 \\
\hline Phase IV: Test Planning and Execution & \\
\hline Functional test case execution & Sprint 14 \\
\hline Performance test case execution & Sprint 15 \\
\hline Performance tuning and test case remediation complete & Sprint 16 \\
\hline Performance test case re-executed & Sprint 17 \\
\hline Performance documentation/requirements updated & Sprint 17 \\
\hline Phase V: Production Migration Analysis & \\
\hline Updated iRODS Requirements Document & Sprint 18 \\
\hline Updated iRODS Production Architecture Design & Sprint 18 \\
\hline iRODS Production Implementation Plan & Sprint 19 \\
\hline Updated User and System Admin Guides & \\
\hline
\end{tabular}

\subsection{Implementation plan}

As part of the Schedule Management Plan, a backlog of items will be created in the JIRA project management software. These items will contain a more detailed task list to facilitate Agile sprint planning with all relavent stakeholders. The sprint plans will be approved by the PM and be maintained in the JIRA instance. 
Each backlog item will contain or reference the following, where applicable:

- Requirements - brief description of the functional and performance requirements of the systems being migrated/developed.

- Resource Assignments - the person/group responsible for the work item.

- Assumptions - assumptions that are made in order to be able to complete the work item (e.g., a related dependency being completed).

- Design - system drawings and narrative describing, in detail. the component being developed/deployed.

- Quality Checklist - subset of the requirements defined as critical to project acceptance.

- These requirements will subsequently be evaluated according to the Quality Management Plan.

\subsection{Scrum agile process}

The iRODS project will be executed using a scrum agile process (Figure 1). Work will be planned and executed by the Geocent Implementation Team using 2-wk sprints. The ERS PM will prioritize backlog items that the team will review and commit to during sprint planning meetings. At the completion of each sprint, the team will conduct a sprint review meeting to provide sprint accomplishments and perform any relevant demonstrations for the ERS PM and stakeholders. The scrum agile process provides a framework to ensure that all stakeholders are regularly updated, have a touchpoint to provide input, and the project can adjust to change more easily.

Scrum meetings that will be held each sprint:

- Backlog grooming - The ERS PM and/or ERS Project Administrator will meet with the Geocent Technical Lead, prior to sprint planning, to ensure backlog items are ready (i.e., dependencies are met and acceptance criteria is defined), and that the correct priority is assigned to the work items.

- Sprint planning - The ERS PM, ERS Project Administrator, Geocent Implementation Team, and any other resources identified by the ERS PM will meet to review the backlog and commit to the highest priority work items the team feels they can complete for the sprint. The sprint planning meeting will immediately follow the sprint review meeting. 
- Sprint review - The Geocent Technical Lead will present a status on all sprint items committed to by the team. Any applicable demonstrations will be performed during this meeting. The ERS PM may invite different stakeholders to attend depending on the items anticipated being discussed/demonstrated during the meeting.

- Daily standup - The Geocent Implementation Team will meet daily for a brief 15 min meeting to discuss what was completed yesterday, what is planned for today, and identifying any impediments preventing the team from meeting sprint goals.

Figure 1. Scrum agile process overview.

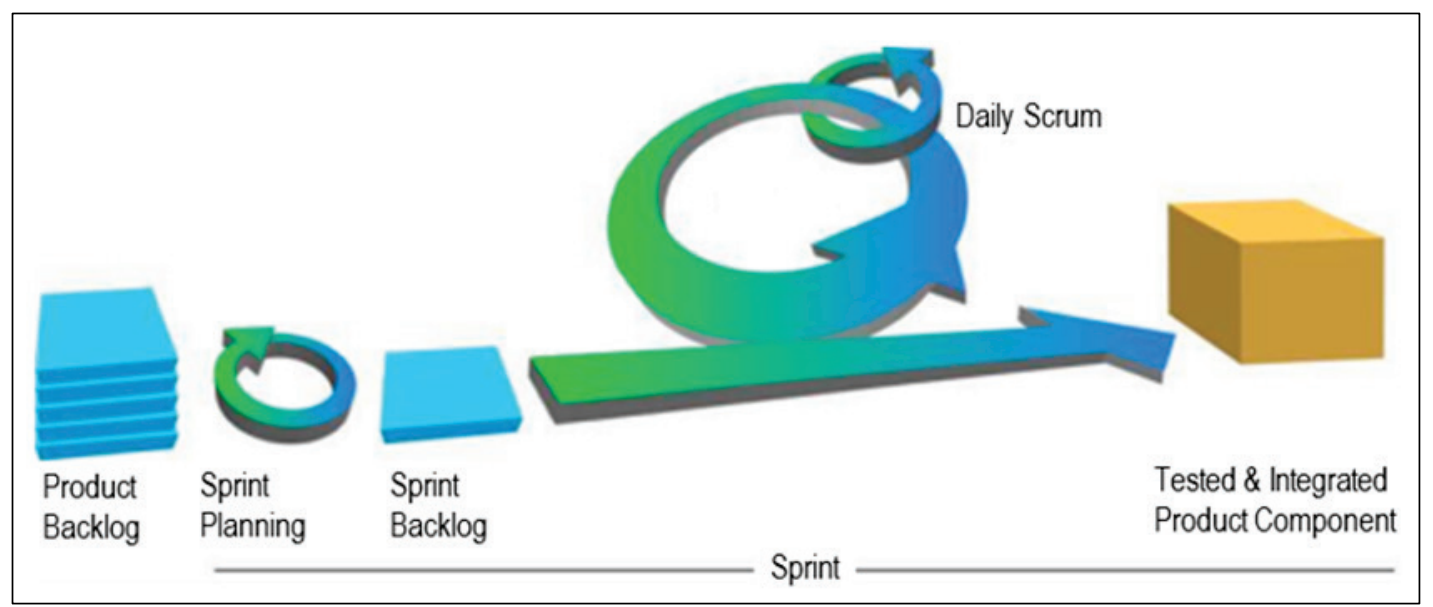




\section{Cost/Budget Management}

The PM will be responsible for managing and reporting on the project's costs. The initial budget is based on the labor required to develop and operate the iRODS prototype within the HPC environment. Any additional labor or training resources required should be promptly identified to the PM. If these are determined to be due to a change in scope, the scope management process previously identified will be invoked to modify the scope definition. The PM will ultimately need to approve any additionally requested resources for labor. 


\section{Quality Management}

All members of the iRODS project team will play a role in quality management. It is imperative that the team ensures work is completed at an adequate level of quality from individual tasks to the final testing activities completed in the HPC environment. The following are the quality management roles and responsibilities for this project:

- The PM is responsible for quality management throughout the duration of the project, implementing this Quality Management Plan, and ensuring all tasks, processes, and documentation are compliant with the plan. The PM will work with the project team to establish acceptable quality standards. They are also responsible for communicating and tracking all quality standards to the project team and stakeholders.

- The other members of the project team, as well as the stakeholders, will be responsible for assisting the PM in the establishment of acceptable quality standards. They will also work to ensure all quality standards are met and communicate any concerns regarding quality to the PM.

The PM, in coordination with the ERS Test Teams, will identify a list of critical technical and performance requirements as part of the prototype implementation. These requirements will form a checklist, which will be evaluated before the acceptance of the prototype close-out. Each requirement will be assessed and rated by the project team, which will be facilitated by the PM. Ratings of "Meets," Partially Meets," or "Does Not Meet" will be given .

- Meets - capability performs at or above expected levels.

- Partially Meets - capability performs some of what was desired / expected, but requires additional work to achieve fully acceptable performance.

- Does Not Meet - required capability is missing or performs unsatisfactorily. 
The initial measure for quality assurance will be based on this evaluation. The standard is defined as the following: $100 \%$ of the critical requirements must achieve a "Meets" or "Partially Meets" rating with a documented approach and timeline detailing how the requirement will be met through subsequent development during operations. The evaluated checklist will be presented to the PM for acceptance. 


\section{Staffing Management}

The iRODS Project will consist of a matrix structure with support primarily from within ERS, HPC, and Geocent. All government organizations will be responsible for managing the specific staffing requirements for project deliverables and tasks assigned to them. 


\section{Roles and Responsibilities}

This chapter lists the anticipated primary roles and responsibilities of the project. Some of these are broad team descriptions, which will be staffed by the appropriate organizational manager.

\section{Organizational Roles:}

- ERS Leadership

- ERS Test Team

- HPC Leadership

- HPC Team

- Geocent Implementation Team

- Information Assurance (IA) Team

\section{Staffing Roles:}

- ERS PM

- ERS Project Administrator

- ERS Team Leads

- Geocent Technical Lead/Architect

- Geocent System Administrator

- Geocent Software Engineer

- Geocent System Integrator

- HPC Infrastructure Operator

\subsection{Organizational roles}

\subsubsection{ERS leadership}

ERS is responsible for the project execution of the iRODS project. In general, ERS will manage and lead the iRODS project and will ensure deliverables align with business requirements and business needs. Specifically, the team will support the iRODS project in the following ways:

- Acting as the ultimate accountable and responsible organization for the success of the iRODS project,

- provide project guidance and direction to support the execution of the iRODS project to include planning, design, implementation, and testing per the defined requirements, 
- provide project planning and controls including developing a detailed project plan,

- provide ERS and HPC leaders visibility into project health, progress, and issues,

- collaboratively work with HPC and the Geocent Implementation Team to ensure the solution is implemented on schedule and within budget,

- ensure assigned HPC and Geocent activities align with project scope and direction, and

- assist with eliminating barriers, mitigating risks, and resolving issues encountered during the iRODS project implementation.

\subsection{ERS Test Team}

The ERS Test Team consists of individual work package leads selected by the ERS PM to represent the work packages selected for iRODS prototype testing. The ERS Test Team will be responsible for identifying, or creating, the data needed to complete their test cases as well as the migration of the data into the iRODS test environment. Specifically, the team will support the iRODS project in the following ways:

- Identify/create data to be used for iRODS functional testing,

- participate in the development of test cases to be used in the Quality Management Plan,

- provide input to the ERS PM on web GUI and dashboard needs,

- provide feedback in sprint review meetings, and

- conduct testing to support functional and performance test events.

\subsubsection{HPC leadership}

The HPC leadership will be responsible for identifying hardware resources available to use for the iRODS prototype. This team will assist in collaboratively working with the ERS leadership to identify and mitigate risks of the iRODS project and provide necessary support and guidance to facilitate a successful implementation in the test environment. Specifically, the team will support the iRODS project in the following ways:

- identify hardware resources available for use during the iRODS prototype phase,

- identify technical resources that can be available to configure the provided hardware, 
- work with the ERS leadership to address any risks / issues and develop mitigation plans, and

- participate in meetings held by the ERS PM as needed to facilitate a successful implementation of the iRODS prototype in the HPC test environment.

\subsubsection{HPC team}

The HPC team will be responsible for providing the required hardware resources (i.e., servers, networking, storage) to support the iRODS prototype. This team will provision the virtual machines, configure network ACLs, provide user account access to the Geocent team, and provide guidance to the Geocent team regarding HPC processes and procedures. Specifically, the team will support the iRODS project in the following ways:

- provide hardware resources (i.e., server - virtual machines, networking, storage) for the iRODS prototype,

- provide technical resources in support of the project and key tasks assigned to the HPC team,

- provision virtual machines according to the specifications in the iRODS Architecture Design Document within the iRODS test subnet,

- provide administrative accounts for the approved Geocent Implementation Team Members,

- provide technical advice in support of the key HPC integration tasks (e.g., Kerberos, Splunk, etc.),

- provide technical guidance and recommendations to ERS during prototype testing,

- identify potential issues and risks with recommended configurations, and

- provide status updates on HPC team assigned tasks.

\subsubsection{Geocent Implementation Team}

The Geocent Implementation Team will install and configure the software required to support the iRODS prototype on each of the virtual instances provided by the HPC team. This team will integrate the necessary software within the test environment and support the functional, performance, and fail-over testing that is in scope for the testing activities. 
The Geocent Implementation Team will also be responsible for the technical implementation of the iRODS prototype. Specifically, the team will support the iRODS project in the following ways:

- install and configure software on the virtual machine infrastructure for the iRODS prototype,

- provide technical advice in support of the key data migration tasks,

- provide technical resources in support of the project and key tasks,

- provide technical guidance and recommendations to ERS during prototype testing,

- provide information and status on iRODS prototype applications and tools,

- identify potential issues and risks with recommended configurations,

- support ERS on implementation process and tasks, risks, issue resolution, and requirements, and

- provide status updates on Geocent Implementation Team assigned tasks.

\subsubsection{IA team}

The IA team ensures compliance with required Department of Defense (DoD) certification and accreditation (C\&A) standards. The IA team is responsible for detailing the C\&A documentation requirements for operating within the ERDC DSRC. This team will participate in Technical Design Review meetings and provide guidance to the ERS PM to meet project objectives.

\subsection{Staffing roles}

\subsubsection{ERS PM}

The ERS PM is the authorized manager of the iRODS project. The PM will coordinate with all organizational managers in order to identify and assign resources for the project. The appropriate organizational manager must approve all resources before the resource may begin any project work. The $\mathrm{PM}$ will also be responsible for implementing the Quality Management Plan and ensuring all tasks, processes, and documentation are compliant with the plan. 


\subsubsection{ERS Project Administrator}

The ERS Project Administrator performs administrative tasks including status tracking, scheduling, and general support. They are responsible for planning, creating, and/or managing all work activities, variances, tracking, reporting, communication, and coordination with other organizational managers.

\subsubsection{ERS Team Leads}

The ERS Team Leads are responsible for representing their specific work packages' needs during the iRODS project. The Team Leads must identify existing data, or create data, for functional testing within the iRODS test environment. They will provide input to the ERS PM to include needed features of the iRODS prototype needed by their work package.

\subsubsection{Geocent Technical Lead/Architect}

The Geocent Technical Lead/Architect is responsible for technical design artifacts, leading technical discussions, presenting status updates during sprint review meetings, and collaborating with the ERS PM during backlog grooming sessions to ensure the Geocent Implementation Team tasks are prioritized and ready for sprint planning. The Geocent Technical Lead/Architect provides input to test planning and execution, as well as supporting all tasks assigned to the Geocent Implementation Team.

\subsubsection{Geocent System Administrator}

The Geocent System Administrator is responsible for system administration tasks including operating system management, patching, and application management. They will support the ERS Test teams during the test phases and support other tasks assigned to the implementation team.

\subsubsection{Geocent Software Engineer}

The Geocent Software Engineer is responsible for the development tasks within the Web GUI, auditing dashboard(s), and custom iRODS rule development. They support the data migration/staging activities and support the overall functional and performance test activities. 


\subsubsection{Geocent System Integrator}

The Geocent System Integrator is responsible for system integration tasks between iRODS components and existing HPC infrastructure components (i.e., Kerberos, Splunk, etc.). Additionally, the Geocent System Integrator will support the environment build-out and database administration tasks, as well as supporting other tasks assigned to the implementation team.

\subsubsection{HPC Infrastructure Operator}

The HPC Infrastructure Operator is responsible for creating and managing the HPC hardware infrastructure, including provisioning virtualized instances, networking components, storage resources, and user accounts. They will participate in the Technical Design meetings and advise the ERS $\mathrm{PM}$ on HPC processes and procedures. 


\section{Communications Management}

This Communications Management Plan sets the communications framework for this project. It will serve as a guide for communications throughout the life of the project and will be updated as communication requirements change. This plan identifies and defines the roles of Project Team members as they pertain to communications. It also includes a communications matrix, which maps the communication requirements of this project, and communication conduct for meetings and other forms of communication. A project team directory is also included to provide contact information for all stakeholders directly involved in the project.

The PM will take the lead role in ensuring effective communications on this project. The communications requirements are documented in the communication matrix found in Table 2 . The communication matrix (Table 2) will be used as the guide for what information to communicate, who is to do the communicating, when to communicate, and to whom to communicate.

Table 2. Communication matrix.

\begin{tabular}{|c|c|c|c|c|c|c|}
\hline $\begin{array}{c}\text { Communication } \\
\text { Type }\end{array}$ & Description & Frequency & Format & Participants & Deliverable & Owner \\
\hline $\begin{array}{c}\text { Bi-weekly Sprint } \\
\text { Review }\end{array}$ & $\begin{array}{c}\text { Summary of } \\
\text { sprint status and } \\
\text { applicable } \\
\text { demonstrations }\end{array}$ & $\begin{array}{c}\text { Bi-weekly } \\
\text { (Every 2 } \\
\text { weeks) }\end{array}$ & $\begin{array}{c}\text { In } \\
\text { Person }\end{array}$ & $\begin{array}{c}\text { Project } \\
\text { Manager, } \\
\text { Geocent } \\
\text { Team and } \\
\text { Stakeholders }\end{array}$ & $\begin{array}{c}\text { Sprint Review } \\
\text { Presentation } \\
\text { and applicable } \\
\text { demonstrations }\end{array}$ & $\begin{array}{c}\text { Geocent } \\
\text { Technical } \\
\text { Lead }\end{array}$ \\
$\begin{array}{c}\text { Technical } \\
\text { Design Review }\end{array}$ & $\begin{array}{c}\text { Review of any } \\
\text { technical } \\
\text { designs or work } \\
\text { associated with } \\
\text { the project }\end{array}$ & As Needed & $\begin{array}{c}\text { In } \\
\text { Person }\end{array}$ & $\begin{array}{c}\text { Geocent } \\
\text { Team, HPC } \\
\text { Team, and IA } \\
\text { Team }\end{array}$ & $\begin{array}{c}\text { Technical } \\
\text { Design Docs }\end{array}$ & $\begin{array}{c}\text { Project } \\
\text { Manager }\end{array}$ \\
$\begin{array}{c}\text { Alerts key } \\
\text { Notifical Risk }\end{array}$ & $\begin{array}{c}\text { stakeholders of } \\
\text { new risks and } \\
\text { mitigations }\end{array}$ & As Needed & Email & $\begin{array}{c}\text { Program } \\
\text { Manager }\end{array}$ & $\begin{array}{c}\text { Updated risk } \\
\text { tracker log }\end{array}$ & $\begin{array}{c}\text { Project } \\
\text { Manager }\end{array}$ \\
\hline $\begin{array}{c}\text { Project Issue } \\
\text { Notification }\end{array}$ & $\begin{array}{c}\text { Alerts PM of new } \\
\text { issues }\end{array}$ & As Needed & Email & $\begin{array}{c}\text { Project } \\
\text { Manager }\end{array}$ & $\begin{array}{c}\text { Updated Issue } \\
\text { Tracker log }\end{array}$ & $\begin{array}{c}\text { Project } \\
\text { Team }\end{array}$ \\
\hline
\end{tabular}




\subsection{Communications conduct}

\subsubsection{Meetings}

The PM will distribute a meeting agenda prior to any scheduled meeting and all participants are expected to review the agenda prior to the meeting. It is imperative that all participants arrive to each meeting/dial in on time. Meeting minutes will be distributed after each meeting is completed.

\subsubsection{E-mail}

All e-mail pertaining to the iRODS Project should be professional, free of errors, and provide brief communication. Email should be distributed to the correct project participants in accordance with the communication matrix (Table 2) based on its content. If the e-mail is bringing issue forward, it should discuss what the issue is, provide a brief background, and provide a recommendation to correct the issue. The PM should be included on any email pertaining to the iRODS Project (Table 3).

Table 3. Project team directory.

\begin{tabular}{|l|l|l|l|}
\hline Name & Title & Email & Phone \\
\hline Dr. Owen Eslinger & ERS Program Manager & Owen.J.Eslinger@erdc.dren.mil & (601) 634-2117 \\
\hline Mr. Kevin Winters & ERS Project Manager & Kevin.D.Winters@erdc.dren.mil & (601) 634-2102 \\
\hline TBD & ERS Project Administrator & & \\
\hline TBD & ERS Team Lead (JAIC) & & \\
\hline TBD & $\begin{array}{l}\text { ERS Team Lead (Data } \\
\text { Analytics) }\end{array}$ & & \\
\hline TBD & $\begin{array}{l}\text { ERS Team Lead } \\
\text { (Environmental Simulation) }\end{array}$ & & \\
\hline TBD & $\begin{array}{l}\text { ERS Team Lead (Sensor } \\
\text { Systems) }\end{array}$ & & \\
\hline TBD & $\begin{array}{l}\text { ERS Team Lead (Rapid } \\
\text { Prototyping) }\end{array}$ & & (601) 807-1760 \\
\hline Mr. Brian Priest & $\begin{array}{l}\text { Geocent Technical } \\
\text { Lead/Architect }\end{array}$ & Brian.Priest@geocent.com & \\
\hline TBD & Geocent Software Engineer & & \\
\hline TBD & $\begin{array}{l}\text { Geocent System } \\
\text { Administrator }\end{array}$ & & \\
\hline TBD & Geocent System Integrator & & \\
\hline TBD & $\begin{array}{l}\text { HPC Infrastructure } \\
\text { Operator }\end{array}$ & & \\
\hline
\end{tabular}




\subsubsection{Informal communication}

While informal communication is a part of every project and is necessary for successful project completion, any issues, concerns, or updates that arise from informal discussion between team members must be communicated to the PM so the appropriate action may be taken. 


\section{Risk Management}

A continuous risk management process intended to minimize risk impact will be implemented. Early identification of risks will be obtained through regular status reporting, ensuring risks are cited and controlled before it can cause critical problems.

The risk management approach will consist of the following parts:

- Identification of possible obstacles to project success

- Analysis of their root causes, as well as the likelihood and consequences of such occurrences

- Planning of mitigation approaches for identified risks

- Monitoring of the project to determine the occurrence of a risk factor

- Review of risk factors to evaluate possible changes in their likelihood or consequence

- Control of risk consequences by the initiation of mitigation strategies

- Modification (if necessary) of mitigation strategies as circumstances change

- Communication of risk factors and their respective mitigation strategies with the PM

Identified risks will be tracked with a simple spreadsheet log and will include the following attributes:

- ID: Risk Tracking Number

- Risk Description: This is a brief description of the risk. It lists the impacts on the project and describes how to monitor and detect that the risk has occurred or is about to occur. Included are such items as metrics and thresholds, test results and specific events

- Risk Level: Low, Moderate, High, Extreme. Calculated from the combination of Likelihood and Impact

- Likelihood: (1) Not Likely, (2) Low Likelihood, (3) Likely, (4) Highly Likely, (5) Nearly Certain

- Impact: Severity: (1) Minimal, (2) Minor, (3) Moderate, (4) Significant, (5) Severe

- Areas of Impact: (C) Cost, (R) Resources, (S) Schedule, (T) Technical, (P) Programmatic

- Mitigation Approach: This describes what is currently being done on the project to reduce the impact of the risk. It also describes what the 
course of action will be if the risk does materialize, such as an alternate solution, reduction in functionality, or other actions.

When a new risk is identified as extreme, the PM will be notified immediately and a resulting mitigation approach will be developed and agreed upon. Risks of other severity and probability will be managed by the PM and appropriate mitigation steps developed. The PM will receive a weekly update report describing the status of all identified risks. The Risk Tracking Log will be maintained and stored in a mutually agreeable location.

Throughout execution of the project, the success of all developed risk mitigations will be evaluated and the approach updated as required to ensure risk impact is being appropriately minimized. 


\section{Issue Management}

With a diverse team consisting of several internal organizations (ERS, HPC, IA) and supporting contractor teams, architectural, technical, cost, and compliance issues are likely to arise. All issues will be promptly captured and recorded within the Issue Log. Should any issues arise that cannot be adjudicated promptly by the PM, they will be presented to the $\mathrm{PM}$ for resolution. The PM will be responsible for preparing an issue summary for review and will coordinate any required issue review meeting with all stakeholders.

The Issue Log will capture the following attributes:

- Issue: Tracking number.

- Description: Detailed description of the issue.

- Priority (H,M,L): High, Medium or Low priority.

- Category: Architecture, Technology, Resources, Information Assurance (IA), or Other.

- Reported By: Who reported the issue?

- Assigned To: Who is the issue assigned to?

- Status: Open, or Closed.

- Date Resolved: On what date was the issue resolved?

- Resolution/Comments: What was the resolution or what is being done to resolve the issue?

The Issue Log will be maintained and stored in a mutually agreeable location. 


\section{Responsible, Accountable, Consulted, and Informed (RACI) Diagram}

Table 4 provides the Responsible, Accountable, Consulted, and Informed (RACI) diagram outlining the key tasks for the iRODS prototype. This chart highlights the major organizations and assigns a role to a specific task located on the far-left column. The definitions of the category designations are as follows:

$\mathbf{R}=$ Responsible. The " $R$ " indicates the group has the ownership to complete a task. Multiple organizations can have an " $\mathrm{R}$ " assigned at a time.

A = Accountable. The "A" indicates the group is ultimately responsible for the thorough completion of the task. Only one group can be accountable for an individual task, but may be concurrently responsible "R" and accountable "A."

$\mathbf{C}=$ Consulted. The " $\mathrm{C}$ " indicates a group is required to provide feedback to a certain task. This is a two-way communication and the input provided by the group may be incorporated within the given task.

I = Informed. The "I" indicates groups that need to be kept up to date on the progress of a given task. This does not require the group to provide feedback and is considered one-way communication. 
Table 4. RACl diagram.

\begin{tabular}{|c|c|c|c|c|}
\hline $\begin{array}{l}\text { Key: } \\
R=\text { Responsible } \\
A=\text { Accountable } \\
C=\text { Consulted } \\
\text { I = Informed }\end{array}$ & 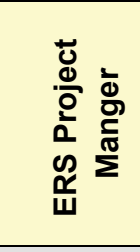 & $\begin{array}{l}\varepsilon \\
\frac{\varepsilon}{\mathbb{J}} \\
\stackrel{-}{0} \\
0 \\
\text { 모 }\end{array}$ & 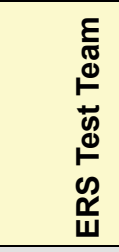 & 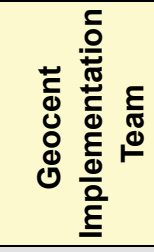 \\
\hline \multicolumn{5}{|l|}{ Kick-off } \\
\hline Kick-off meeting & $\mathrm{R}, \mathrm{A}$ & 1 & 1 & 1 \\
\hline On-boarding of new team members & 1 & - & - & $\mathrm{R}, \mathrm{A}$ \\
\hline Required training/credentialing completed & 1 & - & - & $\mathrm{R}, \mathrm{A}$ \\
\hline Schedule baseline set & $\mathrm{R}, \mathrm{A}$ & $\mathrm{C}$ & $\mathrm{C}$ & $\mathrm{C}$ \\
\hline \multicolumn{5}{|l|}{ Phase I: Test Environment Build-Out } \\
\hline iRODS host VMs and test VLAN are created & 1 & $\mathrm{R}, \mathrm{A}$ & - & 1 \\
\hline iRODS software installed and configured & 1 & - & - & $\mathrm{R}, \mathrm{A}$ \\
\hline Kerberos authentication complete & 1 & $\mathrm{C}$ & - & $\mathrm{R}, \mathrm{A}$ \\
\hline Splunk integration complete & 1 & $\mathrm{C}$ & - & $\mathrm{R}, \mathrm{A}$ \\
\hline Auditing framework installed and configured & 1 & - & - & $\mathrm{R}, \mathrm{A}$ \\
\hline Web GUI installed and configured & 1 & - & - & $\mathrm{R}, \mathrm{A}$ \\
\hline Baseline functional testing executed & 1 & - & 1 & $\mathrm{R}, \mathrm{A}$ \\
\hline Documentation: User Guide complete & I & - & 1 & $\mathrm{R}, \mathrm{A}$ \\
\hline \multicolumn{5}{|l|}{ Phase II: Web GUI Customizations and Auditing Dashboards } \\
\hline Web GUI enhancement designs & C & - & $\mathrm{C}$ & $\mathrm{R}, \mathrm{A}$ \\
\hline Web GUI enhancement prioritization & $\mathrm{R}, \mathrm{A}$ & - & 1 & 1 \\
\hline Auditing dashboard designs & $\mathrm{C}$ & - & C & $\mathrm{R}, \mathrm{A}$ \\
\hline Auditing dashboard prioritization & $\mathrm{R}, \mathrm{A}$ & - & 1 & 1 \\
\hline Web GUI development started & $\mathrm{C}$ & - & $\mathrm{C}$ & $\mathrm{R}, \mathrm{A}$ \\
\hline Auditing dashboards started & C & - & C & $\mathrm{R}, \mathrm{A}$ \\
\hline Web GUI development completed & 1 & - & 1 & $\mathrm{R}, \mathrm{A}$ \\
\hline Auditing dashboards completed & 1 & - & 1 & $\mathrm{R}, \mathrm{A}$ \\
\hline \multicolumn{5}{|l|}{ Phase III: Data Migration for ERS Test Teams } \\
\hline Landing Zones configured & 1 & - & $\mathrm{C}$ & $\mathrm{R}, \mathrm{A}$ \\
\hline Groups/Users permissions configured & A & $\mathrm{R}$ & $\mathrm{C}$ & $\mathrm{R}$ \\
\hline Test cases developed/reviewed & A & - & C & $A, C$ \\
\hline Test data for each team migrated & 1 & - & $\mathrm{R}, \mathrm{A}$ & $\mathrm{C}$ \\
\hline Additional custom test data created/loaded & 1 & - & $\mathrm{R}, \mathrm{A}$ & $\mathrm{C}$ \\
\hline \multicolumn{5}{|l|}{ Phase IV: Test Planning and Execution } \\
\hline Functional test case execution & 1 & - & $\mathrm{R}, \mathrm{A}$ & $\mathrm{R}$ \\
\hline Performance test case execution & 1 & - & 1 & $\mathrm{R}, \mathrm{A}$ \\
\hline Performance tuning and test case remediation complete & 1 & - & 1 & $\mathrm{R}, \mathrm{A}$ \\
\hline Performance test case re-executed & 1 & - & 1 & $\mathrm{R}, \mathrm{A}$ \\
\hline Performance documentation/requirements updated & 1 & - & - & $\mathrm{R}, \mathrm{A}$ \\
\hline
\end{tabular}




\begin{tabular}{|c|c|c|c|c|}
\hline $\begin{array}{l}\text { Key: } \\
R=\text { Responsible } \\
A=\text { Accountable } \\
C=\text { Consulted } \\
\text { I = Informed }\end{array}$ & 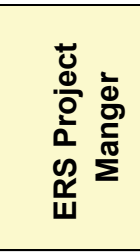 & 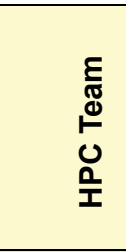 & 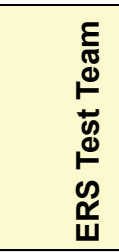 & 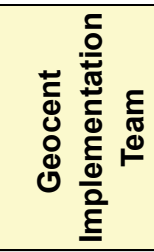 \\
\hline \multicolumn{5}{|l|}{ Phase V: Production Migration Analysis } \\
\hline Updated iRODS Requirements Document & I & 1 & 1 & $\mathrm{R}, \mathrm{A}$ \\
\hline Updated iRODS Production Architecture Design & 1 & 1 & 1 & $\mathrm{R}, \mathrm{A}$ \\
\hline iRODS Production Implementation Plan & I & 1 & 1 & $\mathrm{R}, \mathrm{A}$ \\
\hline Updated User and System Admin Guides & I & 1 & I & $\mathrm{R}, \mathrm{A}$ \\
\hline
\end{tabular}




\section{Conclusion}

This PMP provides guidance on the management of the iRODS Project. The PMP and its associated plans are the primary source of information for how the project will be planned, executed, monitored, controlled, and closed. 


\section{References}

U.S. Army Corps of Engineers / Engineer Research and Development Center. 2019. Engineered Resilient Systems. Vicksburg, MS: Engineer Research and Development Center. (Accessed 4 November 2019).

https://www.erdc.usace.army.mil/Missions/Engineered-Resilient-Systems/. 


\section{Acronyms and Abbreviations}

\begin{tabular}{|l|l|}
\hline Acronym & \multicolumn{1}{|c|}{ Meaning } \\
\hline C\&A & Certification and Accreditation \\
\hline DoD & Department of Defense \\
\hline DSRC & DoD Supercomputing Resource Center \\
\hline ERDC & Engineer Research and Development Center \\
\hline ERS & Engineered Resilient Systems \\
\hline GUI & Graphic User Interface \\
\hline HPC & High-Performance Computing \\
\hline IA & Information Assurance \\
\hline IMS & Integrated Master Schedule \\
\hline iRODS & Integrated Rule-Oriented Data System \\
\hline PM & Project Manager \\
\hline KDC & Key Distribution Center \\
\hline PMP & Project Management Plan \\
\hline RACI & Responsible, Accountable, Consulted, and Informed \\
\hline RFC & Request for Change \\
\hline USACE & U.S. Army Corps of Engineers \\
\hline WBS & Work Breakdown Structure \\
\hline VMs & Virtual Machines \\
\hline
\end{tabular}




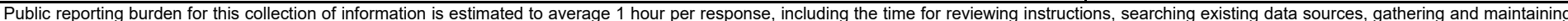

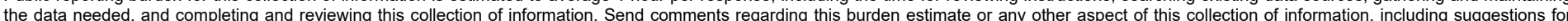

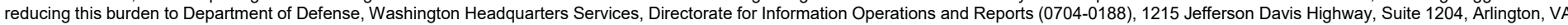

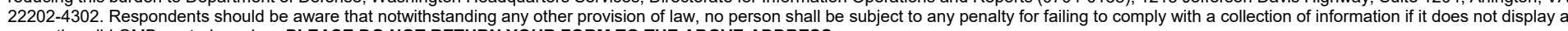
currently valid OMB control number. PLEASE DO NOT RETURN YOUR FORM TO THE ABOVE ADDRESS.
1. REPORT DATE (DD-MM-YYYY) 2. REPORT TYPE
3. DATES COVERED (From - To)

August 2020 Final report

\section{TITLE AND SUBTITLE}

Integrated Rule-Oriented Data System (iRODS) and High Performance Computing (HPC)

Project Management Plan

5a. CONTRACT NUMBER

5b. GRANT NUMBER

5c. PROGRAM ELEMENT NUMBER

\section{AUTHOR(S)}

Kevin D. Winters, Mark A. Cowan, Glover E. George, Megan E. Gonzalez, Brian Priest, Omar Morris, and Jonathan Landrum

5d. PROJECT NUMBER

5e. TASK NUMBER

5f. WORK UNIT NUMBER

92L5D8

\section{PERFORMING ORGANIZATION NAME(S) AND ADDRESS(ES)}

8. PERFORMING ORGANIZATION REPORT NUMBER

U.S. Army Engineer Research and Development Center

Information Technology Laboratory

ERDC/ITL SR-20-11

3909 Halls Ferry Road, Vicksburg, MS 39180-6199

\section{SPONSORING / MONITORING AGENCY NAME(S) AND ADDRESS(ES)}

10. SPONSOR/MONITOR'S ACRONYM(S)

Headquarters, U.S. Army Corps of Engineers

Washington, DC 20314-1000

11. SPONSOR/MONITOR'S REPORT $\operatorname{NUMBER}(\mathbf{S})$

\section{DISTRIBUTION / AVAILABILITY STATEMENT}

Approved for public release; distribution unlimited.

\section{SUPPLEMENTARY NOTES}

\section{ABSTRACT}

This project management plan (PMP) is established to provide guidance on the management of the Integrated Rule-Oriented Data System (iRODS) Project. The PMP and its associated plans are the primary source of information for how the project will be planned, executed, monitored, controlled, and closed. The intended audience of the plan is all project stakeholders including the project manager (PM), Engineered Resilient Systems (ERS), High-Performance Computing (HPC), and the Geocent project team members.

15. SUBJECT TERMS
iRODS (Computer system)

High performance computing

High performance computing--Research
16. SECURITY CLASSIFICATION OF:

\begin{tabular}{l|l}
\hline $\begin{array}{l}\text { a. REPORT } \\
\text { UNCLASSIFIED }\end{array}$ & $\begin{array}{l}\text { b. ABSTRACT } \\
\text { UNCLASSIFIED }\end{array}$ \\
\hline
\end{tabular}

c. THIS PAGE

UNCLASSIFIED 17. LIMITATION
OF ABSTRACT

SAR
18. NUMBER OF PAGES

42
Data curation

Project management 